\title{
Miniature Piezoelectric Hollow Sphere Transducers (BBs)
}

\author{
Sedat Alkoy, Aydin Dogan, Member, IEEE, Anne-Christine Hladky, Philippe Langlet, \\ Joe K. Cochran, and Robert E. Newnham, Member, IEEE
}

\begin{abstract}
Miniature piezoelectric transducers were prepared from millimeter size hollow spheres which were formed from PZT-5A powder slurries using a coaxial nozzle process. After sintering, the spheres were poled in two ways: radially and tangentially. Principal modes of vibration were found to be a breathing mode near $700 \mathrm{kHz}$ and a thickness mode near $13 \mathrm{MHz}$ for the radially poled spheres, and an ellipsoidal, a circumferential, and a breathing mode near 230,350 , and $700 \mathrm{kHz}$, respectively, for tangentially poled spheres. Coupled modes were also observed at higher frequencies. These same modes with similar frequencies were obtained from finite element analysis using the ATILA FEM code, and experimental results were shown to be consistent with the modeling study. Hydrostatic $d_{h}$ coefficients ranged between 700 and $1,800 \mathrm{pC} / \mathrm{N}$, which is considerably higher than the $d_{h}$ of bulk PZT. The hydrophone figure of merits $\left(d_{h} * g_{h}\right)$ were calculated to be between 68,000 and $325,000 * 10^{-15} \mathrm{~m}^{2} / \mathrm{N}$ for various types of poled spheres. These values are three orders of magnitude higher than the bulk PZT figure of merit. Potential applications include ultrasonic imaging, nondestructive testing, and hydrophones.
\end{abstract}

\section{INTRODUCTION}

L EAD ZIRCONATE TITANATE (PZT) based ceramics have $\triangle$ been the leading piezoelectric materials for electromechanical transducers for the last 40 years [1]. However, for both underwater hydrophones and biomedical ultrasound applications, bulk PZT is a poor material for several reasons. The hydrostatic piezoelectric charge coefficient, $d_{h}\left(=d_{33}+2 d_{31}\right)$ of PZT is very low due to the opposing signs of $d_{33}$ and $d_{31}$. The hydrostatic piezoelectric voltage coefficient, $g_{h}\left(=d_{h} / \epsilon_{r} * \epsilon_{o}\right)$ is also low because of the high dielectric constant, $\epsilon_{r}$, of PZT. In addition to those drawbacks, the acoustic impedance matching of PZT with water and the human body (density $\sim 1.0 \mathrm{~g} / \mathrm{cm}^{3}$ ) is poor due to the high density $\left(7.75 \mathrm{~g} / \mathrm{cm}^{3}\right)$ of bulk PZT.

Since the 1980 's attempts have been made to over-

Manuscript received July 2, 1996; accepted April 2, 1997.

This study is partly funded by ONR through contract \# N0001492J1510, and by the Gebze Institute of Technology, Turkey.

S. Alkoy and R. E. Newnham are with the Materials Research Laboratory, Pennsylvania State University, University Park, PA (email: sxa24@psu.edu).

A. Dogan is with the Planning Department, Corporate Research and Development Group, NGK Insulators, Ltd., Suda-cho, Mizuhoku, Nagoya, 467, Japan.

A.-C. Hladky and P. Langlet are with IEMN, Department ISEN, Cedex, France.

J. K. Cochran is with the Georgia Institute of Technology, School of Materials Science and Engineering, Atlanta, GA 30332. come those problems by coupling the ceramic material with polymers [2], [3] and metals [4], [5], and introducing hollow spaces into the transducer structure. These studies succeeded in improving the hydrostatic piezoelectric properties by decreasing the density of the transducer and by amplifying the sensing and actuating characteristics of the ceramic by redesigning the transducer.

In developing new transducers, the biological world has often been used as the inspiration for innovative ideas and new designs. Sharks, fish, and the other inhabitants of the underwater world - the way they talk and listen - can be imitated in piezoelectric transducer designs. The piezoelectric hollow sphere transducers described in this paper and elsewhere [6] are modeled after the inner ear of a fish. The inner ear is made up of inertia-sensing chambers resembling accelerometers. Within each chamber is a dense ear stone (otolith) which vibrates in a near field sound wave. The inertia of the ear stone causes it to lag behind the motion of the fish, and to push against the hair cells lining the chamber (sacculus). On bending, the hair cell membranes deform, stimulating neural transmissions to the brain. Connections to swim bladder of the fish further improve the sensitivity to far-field sound [7].

Directional characteristics are important in designing a transducer for underwater and biomedical applications. Several novel transducers based on a spherical design have been introduced by researchers in order to exploit symmetry to achieve omnidirectional transmit and receive responses. In the area of underwater acoustics, these designs include hollow ceramic spheres with various electrode and poling patterns [8]-[11], spherical arrays of small, planar hydrophones [12], magnetostrictive diaphragms with spherical forms [13], and fiber optic windings wrapped around a resilient ball to form a spherical, omnidirectional acoustic sensor [14]. A similar trend toward spherically shaped transducers is also evident in high frequency biomedical ultrasonic transducers. Recently, a quasi-omnidirectional polymer based transducer was developed by Vilkomerson and Lyons [15] for ultrasonic guidance of catheters. Another study on focused transducers for biomedical ultrasonic imaging proposed a spherical ceramic shell structure with an inherent focal length as a solution [16]. In addition to omnidirectionality, smaller sizes are necessary in some applications. For example, smaller transducers can be used to achieve improved resolution and higher power densities in intravascular image catheters in biomedical ultrasound. Smaller transducers can also be 
used in embedded sensors for nondestructive evaluation, or in flow noise studies of complex surface structures in underwater ultrasound. In comparison with other spherical transducers, the millimeter size, thin wall piezoelectric hollow sphere transducers (BBs) are much smaller in size, and possess a higher radius to thickness ratio $(\mathrm{r} / \mathrm{t})$. BBs are omnidirectional and have a low density $\left(\sim 1.3 \mathrm{~g} / \mathrm{cm}^{3}\right)$, both of which are inherent to the unique structure and design of the transducer. As discussed in the following section, they are produced by a simple, inexpensive process in large numbers, which makes it possible to mass produce throw-away transducers.

In this paper, several poling and electroding configurations for the hollow sphere transducers are introduced. Results of the dielectric and hydrostatic piezoelectric charge coefficient measurements are presented. Vibration modes and their resonance frequencies are identified by the ATILA finite element analysis code, and the results of the modeling study are compared with the experimentally obtained admittance spectra.

\section{Fabrication of PZT Hollow Sphere Transducers}

Green PZT spheres are prepared using a fabrication technique, which was developed by Torobin [17] to produce large numbers of ceramic and metallic hollow spheres. A fine-grained slurry of PZT-501A (Ultrasonic Powders, Inc.) is prepared and injected through a coaxial nozzle with air passing through the center tube. The slurry exits the nozzle in a hollow cylindrical form, but the bottom later closes because of surface tension and hydrostatic pressure. The closed cylinder is inflated into a bubble by the inner air pressure until the pressure equals that of the cylinder. At this critical pressure the bubble closes, and the sphere breaks free. The Torobin process has been shown to be a flexible fabrication technique for hollow spheres of various compositions [18], [19]. It also allows us to tailor the size (1 to $6 \mathrm{~mm}$ in diameter) and the wall thickness (12 to 150 $\mu \mathrm{m})$ of the spheres by changing the viscosity and air jet velocity.

The green PZT spheres are fired at $550^{\circ} \mathrm{C}$ for $30 \mathrm{~min}$ utes for binder burnout, followed by sintering at $1285^{\circ} \mathrm{C}$ for 90 minutes. Sintering is performed in a closed alumina crucible in a bed of PZT powder to minimize lead loss from the spheres. A physical characterization study by Fielding et al. [20] concluded that spheres with a sintered diameter of $\sim 2.76 \mathrm{~mm}$ and a mean wall thickness of $80 \mu \mathrm{m}$ contain microcracks and substantial porosity. The results reported in this paper are obtained from the same batch of spheres. Density measurements using the Archimedes method gave an average bulk sphere wall density of $\sim 7.2 \mathrm{~g} / \mathrm{cm}^{3}$. Although this value is close to the theoretical density of PZT ceramics $\left(\sim 7.75 \mathrm{~g} / \mathrm{cm}^{3}\right)$, the measurement technique is not very sensitive to open pores and microcracks, such as those reported by Fielding et al. [20]. The wall thickness variation was also found to be larger than expected, ranging from 40 to $100 \mu \mathrm{m}$. Improvements in the fabrication process are being undertaken to minimize these defects and wall thickness variations, since they degrade the dielectric and electromechanical properties and disturb the vibration modes of the transducer.

Two poling configurations have been studied: radial poling with inside and outside electrodes, and top-to-bottom poling with two external cap electrodes (Fig. 1). For topto-bottom poling, three symmetric electrode configurations, with electrode gap dimensions (d) of $d=0.79 \mathrm{~mm}$ (Type-1), $\mathrm{d}=1.38 \mathrm{~mm}$ (Type-2) and $\mathrm{d}=1.71 \mathrm{~mm}$ (Type3 ) were investigated. The effect of increasing the poled regions on the capacitance, vibration modes and hydrostatic sensitivity of the transducer was examined.

For radial poling Conductive Silver 200 (Demetron $\mathrm{GmbH}$ ) was used as the inner electrode after drilling an electrode hole with a diameter of about $450 \mathrm{~m}$ prior to the binder burnout step. Silver electrical lead wires were attached, and the electrode hole was sealed using E-solder \# 3021 (Insulating Materials, Inc.) silver epoxy adhesive. A thin layer of gold was deposited as the external electrode for both the radial and top-to-bottom configurations. Poling was carried out with an electric field of $20 \mathrm{kV} / \mathrm{cm}$ at $120^{\circ} \mathrm{C}$ in a silicone oil bath. Prior to the hydrostatic measurements, a soft polyurethane (Dexter Hysol us-0089) coating, with an average thickness of less than $50 \mu \mathrm{m}$, was applied for insulation and to provide extra strength under hydrostatic pressure. The dielectric and piezoelectric measurements reported here were performed on spheres with no protective coating, and the hydrostatic piezoelectric measurements were performed on spheres with the coating.

Three samples for each electrode configuration were prepared and evaluated in order to assess the reproducibility of the results. The results reported in this paper are average values and fall within $a \pm 15 \%$ range.

\section{ATILA Finite Element Code}

ATILA is a finite element code developed by the Acoustics Department at ISEN for the modeling of sonar transducers. It can provide information concerning prestresses, and the behavior under hydrostatic pressure (static analysis), together with the resonant frequencies of various modes and the associated coupling factors (modal analysis), the in-air or in-water impedance and displacement field, the Transmitting Voltage Response and the directivity patterns (harmonic analysis) [21]-[23].

In our study, ATILA was used to identify the modes of vibration and to determine the resonance and antiresonance frequencies of these modes for different electrode configurations. The frequency step used in the finite elements computation was $10 \mathrm{kHz}$ in all cases, except for the thickness mode of radially poled spheres. In the computation of the thickness mode, the frequency step was $100 \mathrm{kHz}$, since the frequency range under investigation was in the $\mathrm{MHz}$. The resultant calculated admittance vs. frequency 


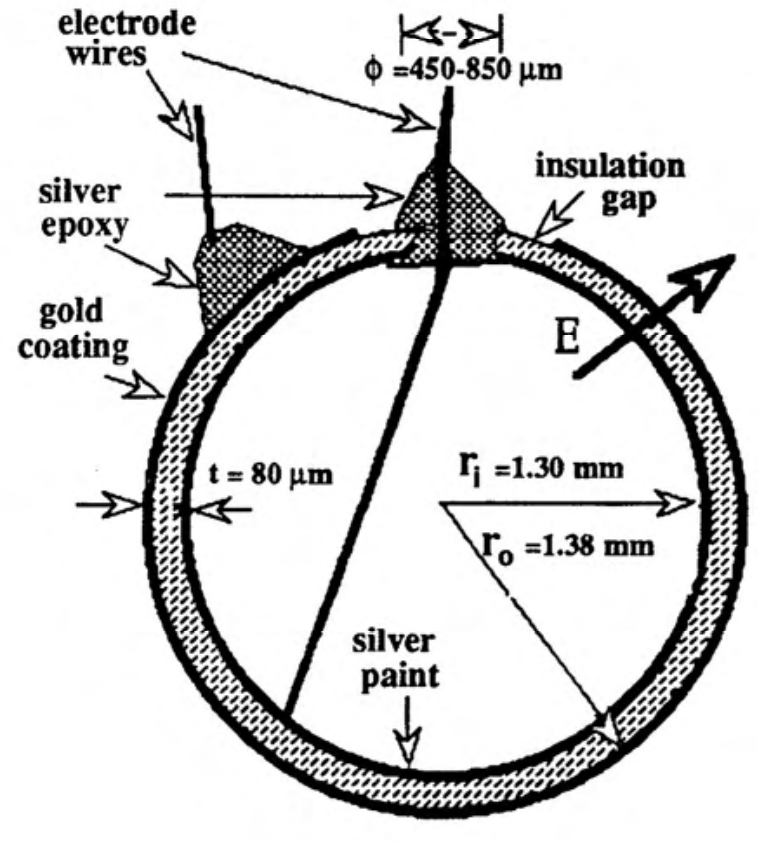

(a)

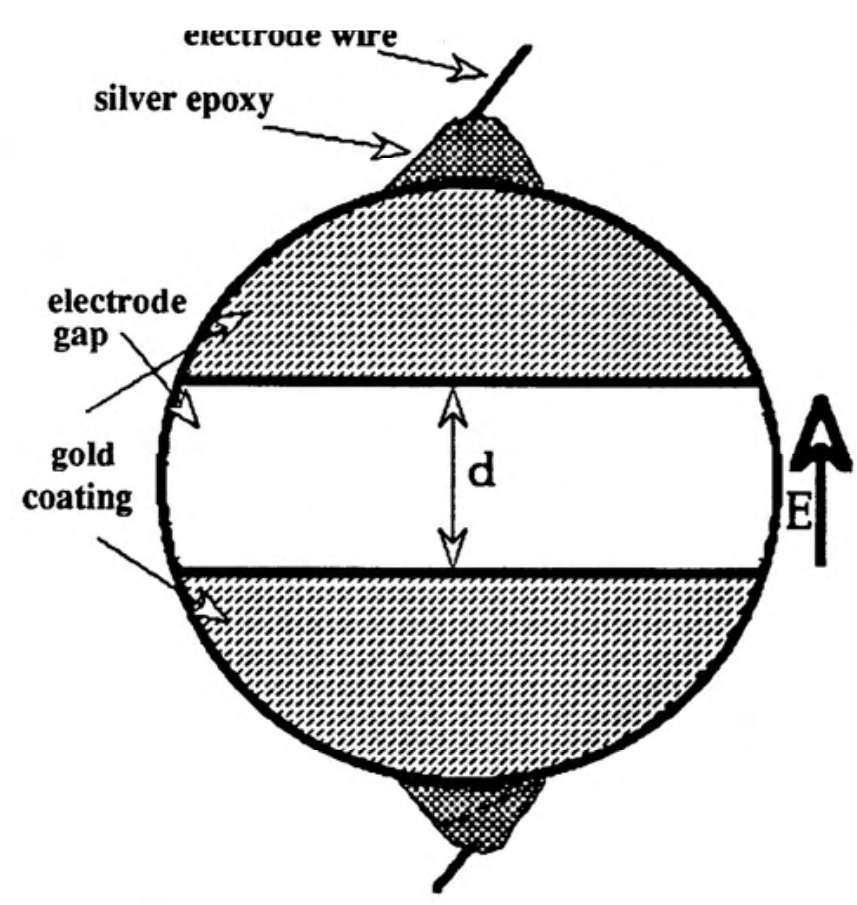

(b)

Fig. 1. Poling configurations: (a) radial poling configuration, (b) topto-bottom poling configuration. spectra are compared with the experimental measurements obtained using an HP 4194-A Impedance/Gain Phase Analyzer. The polyurethane coating was not taken into consideration in the modeling study, since the dielectric and piezoelectric measurements reported here were performed on spheres with no protective coating. The mass of the electrode was assumed to be negligible.

\section{Results And Discussion}

\section{A. Dielectric Characterization}

Dielectric properties of the transducers were measured using a HP 4275-A Multifrequency LCR Meter at $1.0 \mathrm{kHz}$ and 1.0 volt. For radially poled spheres the capacitance was $2,900 \mathrm{pF}$ and the dielectric loss was 0.020 . The dielectric constant $\left(\epsilon_{r}\right)$ of about 1,000 was calculated from the capacitance using the following equation for a spherical capacitor [6]:

$$
C=4 \pi \epsilon_{r} \epsilon_{o}\left(\frac{r_{i} r_{o}}{r_{0}-r_{i}}\right) .
$$

Compared to the dielectric constant of UPI 501A ceramics $\left(\epsilon_{r}=1,850\right)$, this lower than expected dielectric constant can be attributed to wall thickness variations, incomplete shere wall s, capaci(Table I)

Those values are also low compared with the calculated values of 9 to $11 \mathrm{pF}$ computed using a cylindrical tube approximation [6]:

$$
C=\epsilon_{r} \epsilon_{o} \frac{\pi t\left(r_{i}+r_{o}\right)}{d}
$$

As expected, the capacitance of top-to-bottom poled spheres is highly dependent on the electrode size and uniformity.

\section{B. Modes of Vibration of Radially Poled Transducers}

Finite Element Analysis (FEA) of a radially poled hollow sphere suggests two principle modes of vibration as shown in the calculated admittance spectra [Fig. 2(a)]. The first mode is a volumetric expansion and contraction of the sphere, the so-called breathing mode utilizing $d_{31}$. The resonance and antiresonance frequencies of this mode are calculated as $620 \mathrm{kHz}$ and $780 \mathrm{kHz}$, respectively. Materials properties used in these calculations are as follows: $s_{11}{ }^{E}=$ $16.4 * 10^{-12} \mathrm{~m}^{2} / \mathrm{N}, \mathrm{s}_{12}{ }^{E}=-5.74 * 10^{-12} \mathrm{~m}^{2} / \mathrm{N}, \rho=$ $7.75 \mathrm{~g} / \mathrm{cm}^{3}$. Using the relation [24]:

$$
k_{p}^{2}=1-\frac{f_{r}^{2}}{f_{a}^{2}}
$$

the planar coupling factor $\left(k_{p}\right)$ is calculated as 0.61 from the FEA results. The second vibration mode is identified 


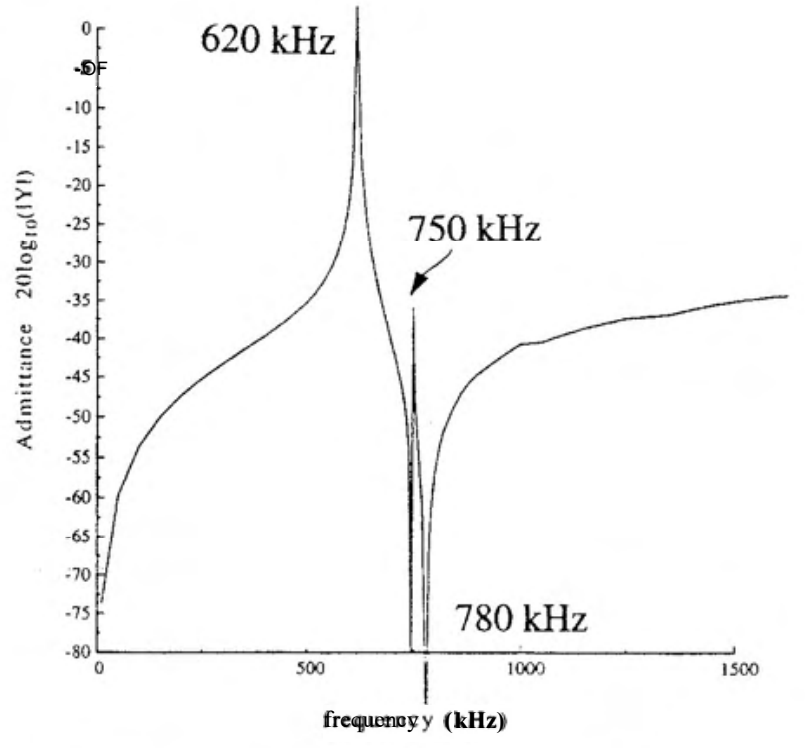

breathimg mode(for a splhere wittha holle)

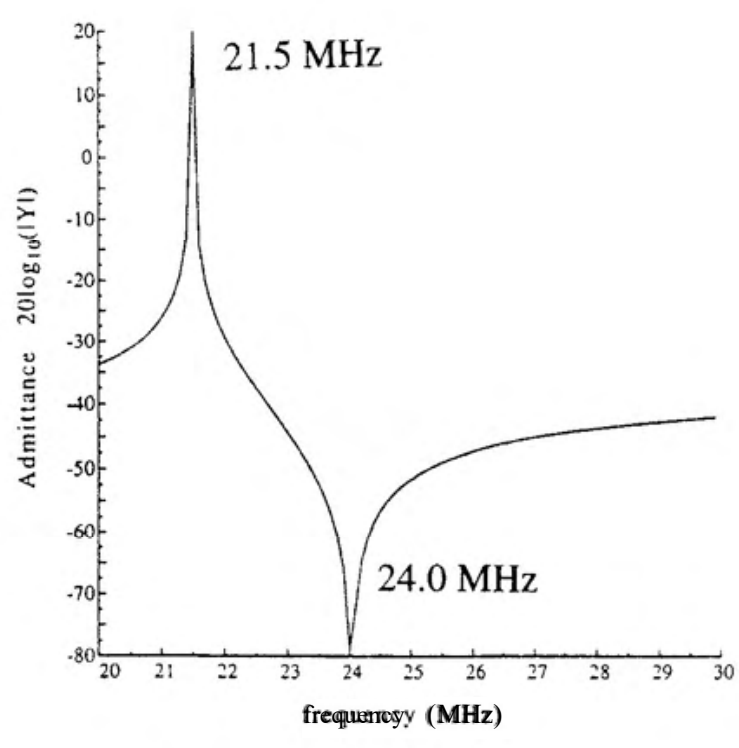

thickmesss modde

(a)

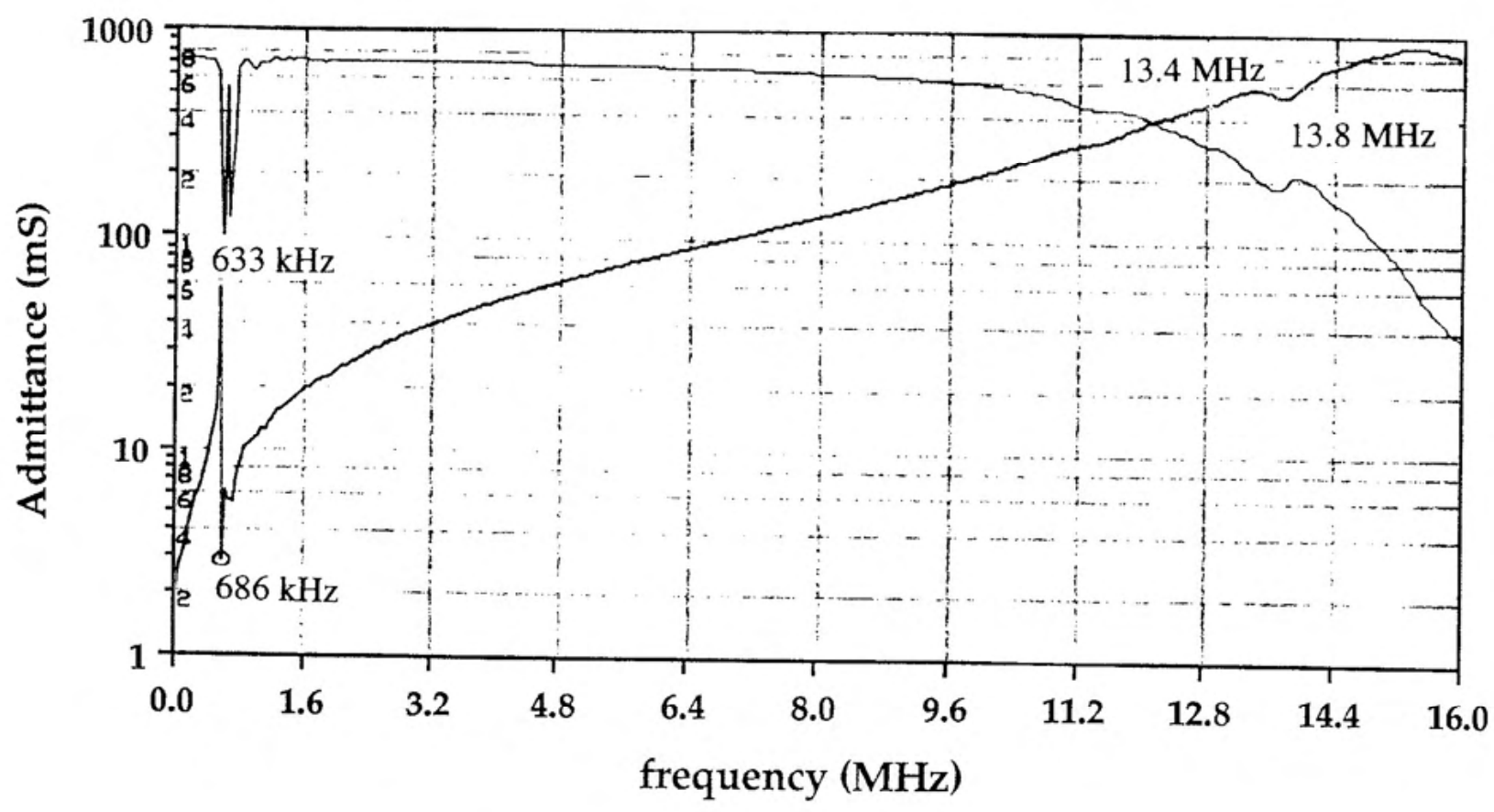

(b)

Fig. 22. Admittancespeptratra of a radiallyypoleled PZT hollow sphlenedransduclercer: (ta)) calcullated, (b) observedt 
TABLE I

Comparison of time Dielectric and Piezoelectric Properties.

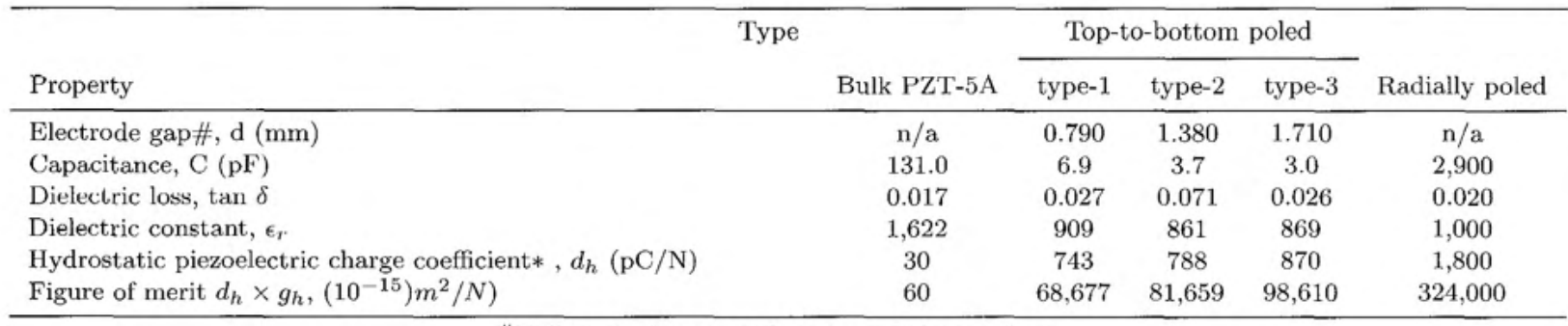

\#Valid only for top-to-bottom poled transducers.

* Determined at $100 \mathrm{psi}$ and $30 \mathrm{~Hz}$.

as the wall thickness mode of the sphere, and the predicted frequencies are $f_{r}=21.5 \mathrm{MHz}$ and $f_{a}=24.0 \mathrm{MHz}$.

In comparison to the FEA results, the experimental admittance spectra obtained from a radially poled sphere transducer with a $\sim 450 \mu \mathrm{m}$ diameter electrode hole, and with an inner radius $\left(r_{i}\right)=1.30 \mathrm{~mm}$, outer radius $\left(r_{o}\right)=$ $1.38 \mathrm{~mm}$, and an average wall thickness $(\mathrm{t})=80 \mu \mathrm{m}$ is shown in Fig. 2(b). The experimental measurements agree well with the FEA results. For the breathing mode the resonance and antiresonance frequencies are $633 \mathrm{kHz}$ and $686 \mathrm{kHz}$, respectively. Since the breathing mode frequency is mainly controlled by the diameter of the sphere [6], the close agreement between the calculated and measured values indicates a fairly uniform diameter for the spheres. The planar coupling factor is calculated as 0.38 from these measurements. The difference between the calculated and observed values of $k_{p}$ is attributed to the electroding problems of the inner sphere surface. However, the resonance and antiresonance frequencies of $13.4 \mathrm{MHz}$ and $13.8 \mathrm{MHz}$, respectively, for the thickness mode vibration - which is determined from the sample given in Fig. 2(b) - is quite different from the values suggested by FEA. The thickness mode itself has only been detected in a few of the samples, and the samples which possess a detectable thickness mode reveal this response as a smooth, broad peak in the admittance spectra. This discrepancy between the calculated and observed values is due to the large variations in wall thickness, as reported previously [20].

\section{Modes of Vibration of Top-to-Bottom \\ Poled Transducers}

A static analysis of the top-to-bottom poling configuration using ATILA to determine the polarization direction gives the electrical potential isocontours shown in Fig. 3 . The results of the analysis indicate that only the unelectroded region between the electrode caps is tangentially poled, and the regions under the electrodes are unpoled and therefore inactive. The electrode gap is expected to control the dielectric and acoustic properties of the transducer. Three types of top-to-bottom poled spheres with increasing electrode gap dimensions were studied. The principal mode of vibration under investigation for top-to-bottom poling configuration is the ellipsoidal dis-

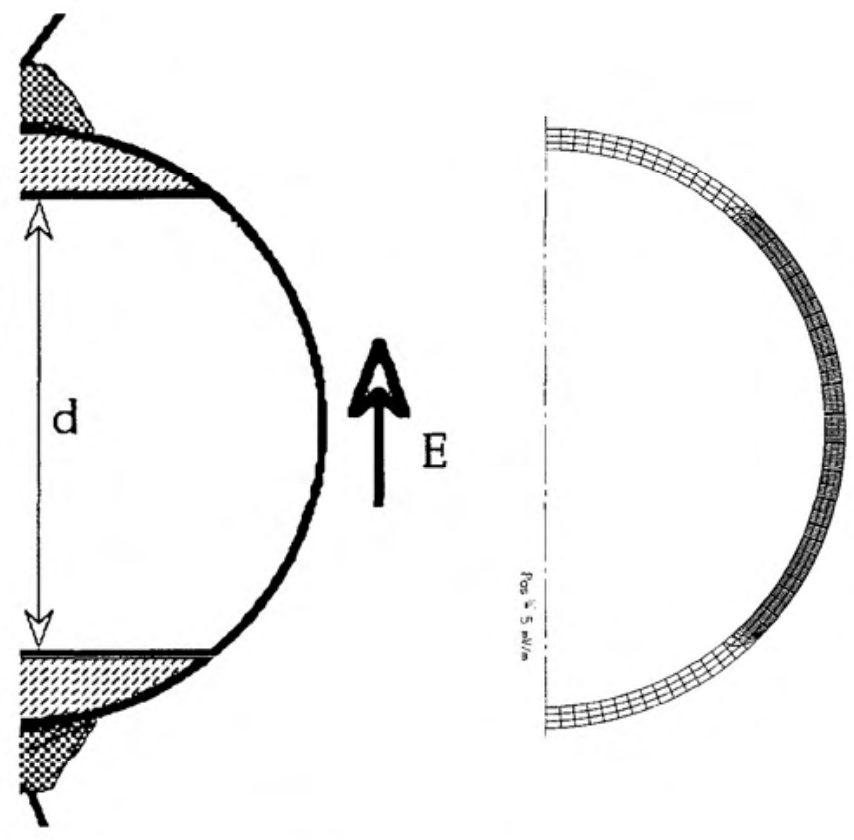

Fig. 3. Polarized region of a top-to-bottom poled sphere.

tortion of the sphere. However, FEA results indicate the presence of two other modes as well: a higher order circumferential mode and a breathing mode, together with higher frequency coupled modes. The admittance spectra obtained from FEA for a sphere with type-3 electrode configuration, i.e., with the largest electrode gap, is compared with the experimentally obtained spectra in Fig. 4. Each major peak in the spectra was studied by FEA, and the displacement fields of these vibrations are shown in Fig. 5.

The calculated and experimental resonance and antiresonance frequencies of all three types of transducers are listed in Table II. It is clear from these values that there is a close match between the modeling and the measurements for the three main vibration modes. However, in the case of the coupled vibration modes, the measured frequencies differ significantly from the values calculated by FEA. This is attributed to the nonuniform wall thickness of the spheres, since these vibrations result from coupling between the ellipsoidal and thick- 
TABLE II

Comparison of the Calculated and Measured Resonance Frequencies.

\begin{tabular}{|c|c|c|c|c|c|c|c|c|c|}
\hline \multirow[b]{2}{*}{ Vibration mode and resonance freq. $(\mathrm{kHz})$} & \multirow[t]{2}{*}{ Type } & \multicolumn{2}{|c|}{ Type-1 } & \multicolumn{2}{|c|}{ Type- 2} & \multicolumn{2}{|c|}{ Type-3 } & \multicolumn{2}{|c|}{ Radial } \\
\hline & & FEA & Exp. & FEA & Exp. & FEA & Exp. & FEA & Exp. \\
\hline Ellipsoidal mode & & 240 & 235 & 240 & 221 & 240 & 233 & $\mathrm{n} / \mathrm{a}$ & $\mathrm{n} / \mathrm{a}$ \\
\hline Higher order & & & & & & & & & \\
\hline circumferential mode & & 390 & 380 & 320 & 308 & 400 & 358 & $\mathrm{n} / \mathrm{a}$ & $\mathrm{n} / \mathrm{a}$ \\
\hline Breathing mode & & 590 & 712 & 590 & 701 & 590 & 708 & 620 & 633 \\
\hline $\begin{array}{l}\text { Ellipsoidal }+ \\
\text { thickness coupled mode } \\
\text { Higher order circumferential }\end{array}$ & & 980 & 1,272 & 980 & 1,226 & 980 & 1,280 & $\mathrm{n} / \mathrm{a}$ & $\mathrm{n} / \mathrm{a}$ \\
\hline + thickness coupled mode & & $\begin{array}{l}1,630 \\
2,330\end{array}$ & $\begin{array}{l}2,005 \\
2,866 \\
3,751\end{array}$ & $\begin{array}{l}1,680 \\
2,480\end{array}$ & 1,987 & 1,750 & not found & $\mathrm{n} / \mathrm{a}$ & $\mathrm{n} / \mathrm{a}$ \\
\hline
\end{tabular}

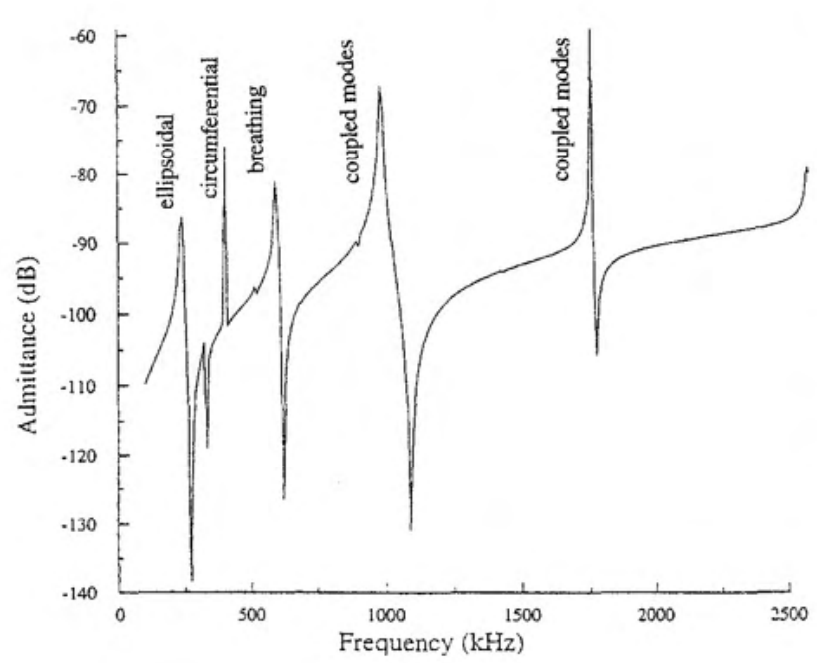

(a)

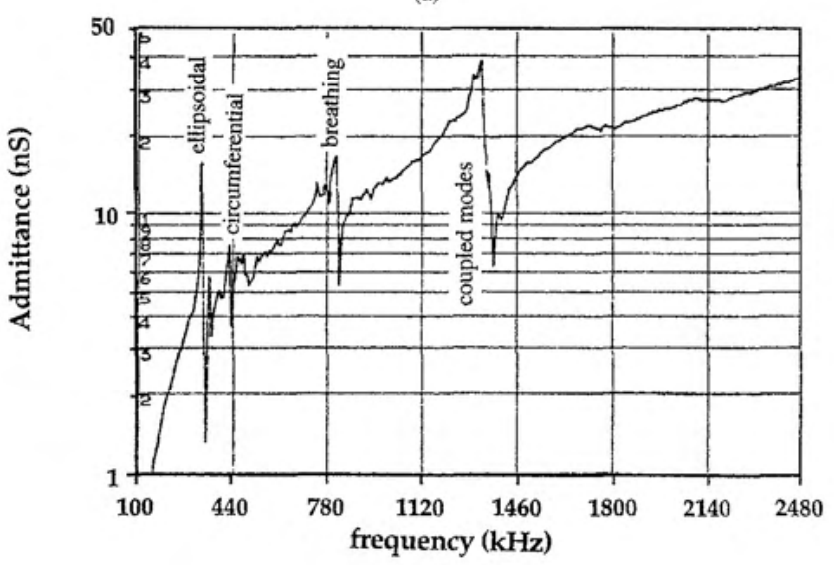

(b)

Fig. 4. Admittance spectra of a top-to-bottom poled PZT hollow sphere transducer: (a) calculated, (b) observed. ness modes, or between the circumferential and thickness modes.

Another result obtained from the experiments and confirmed by the FEA is the introduction of new higher order circumferential-thickness coupled modes created by decreasing the electrode separation (Table II).

\section{Effect of Polymer Coating}

Prior to the hydrostatic measurements, the spheres were dip-coated with polyurethane. Admittance spectra of a radially poled sphere recorded before and after the polymer coating are shown in Fig. 6. It is found that the polymer coating has a clamping effect on the spheres, causing a decrease in the peak amplitude of the breathing mode, and a smoothing of the spectrum. A similar effect is observed for the top-to-bottom poled spheres leading to a slight shift of the ellipsoidal and breathing modes to lower frequencies. This shift is about $10 \mathrm{kHz}$ for the ellipsoidal mode, and 20 to $40 \mathrm{kHz}$ for the breathing mode.

\section{E. Hydrostatic Sensitivity Measurements}

As part of the transducer characterization, hydrostatic measurements were carried out on poled and coated hollow spheres for possible application as underwater hydrophones. The hydrostatic piezoelectric charge coefficient $\left(d_{h}\right)$ was measured in an oil bath at hydrostatic pressures from 100 to 1,000 psi with a $30 \mathrm{~Hz}$ stimulus. A PZT disc was used to calibrate the measurements. The $d_{h}$ results are plotted in Fig. 7(a) as a function of hydrostatic pressure.

The hydrostatic piezoelectric voltage coefficient $\left(g_{h}\right)$, and hydrophone figure of merit of the spheres are defined and calculated from the measured $\mathrm{dh}$ values:

$$
g_{h}=\frac{d_{h}}{\epsilon_{33}}
$$

$$
\text { figure of merit }=d_{h} * g_{h} .
$$

The results are plotted in Fig. 7(b) for the hydrophone figure of merit vs. hydrostatic pressure. The measured and 


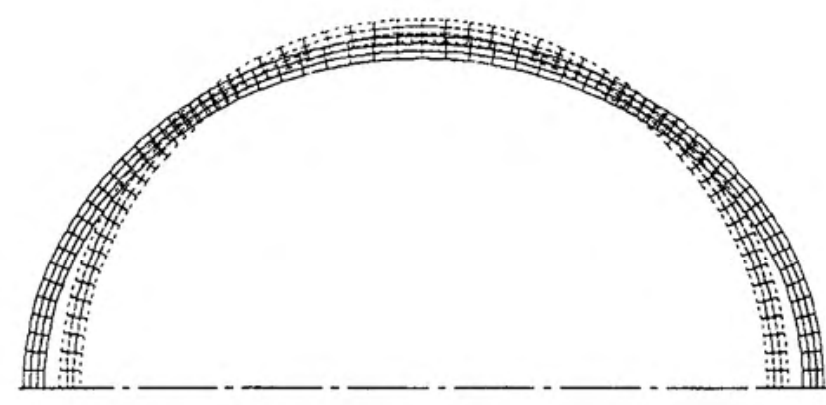

(a)

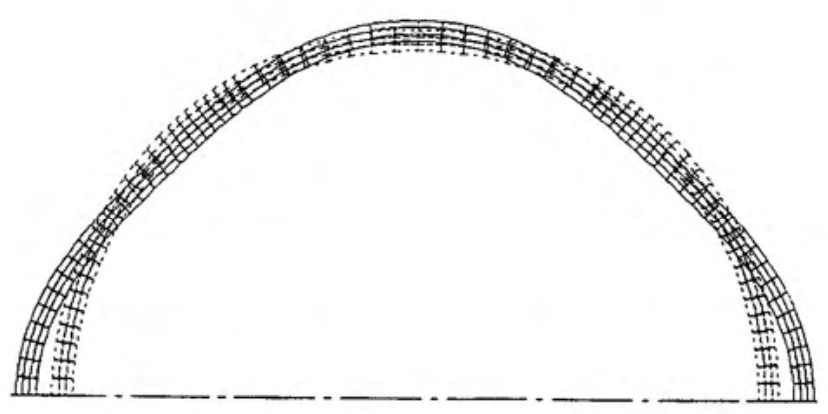

(b)

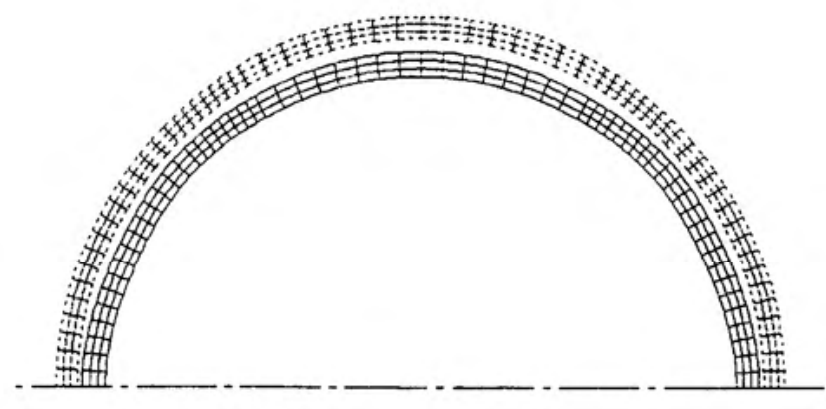

(c)

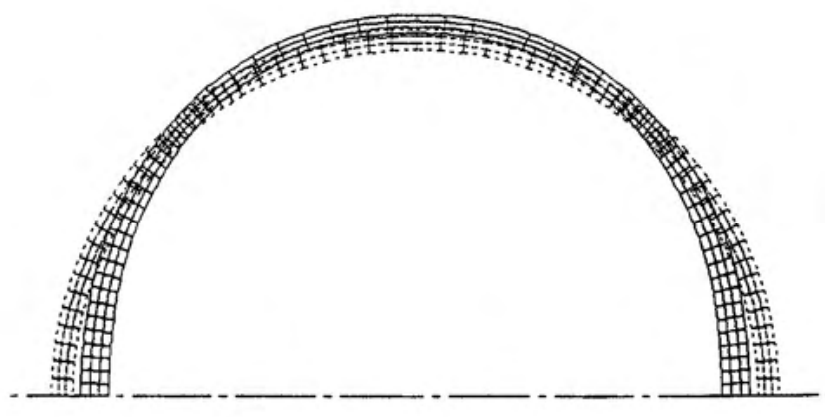

(d)

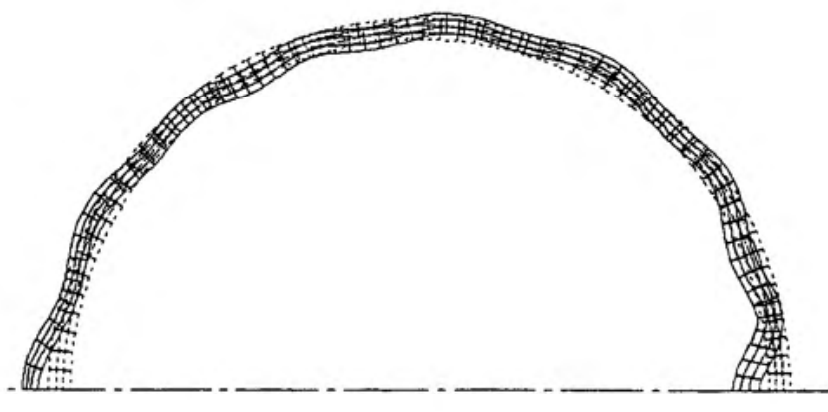

(e)

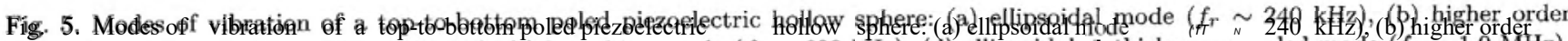

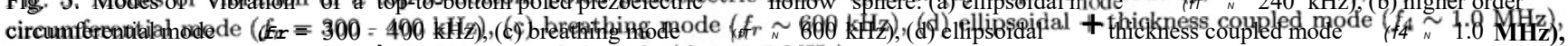

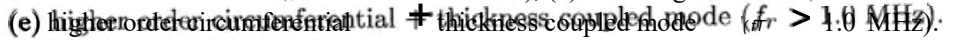




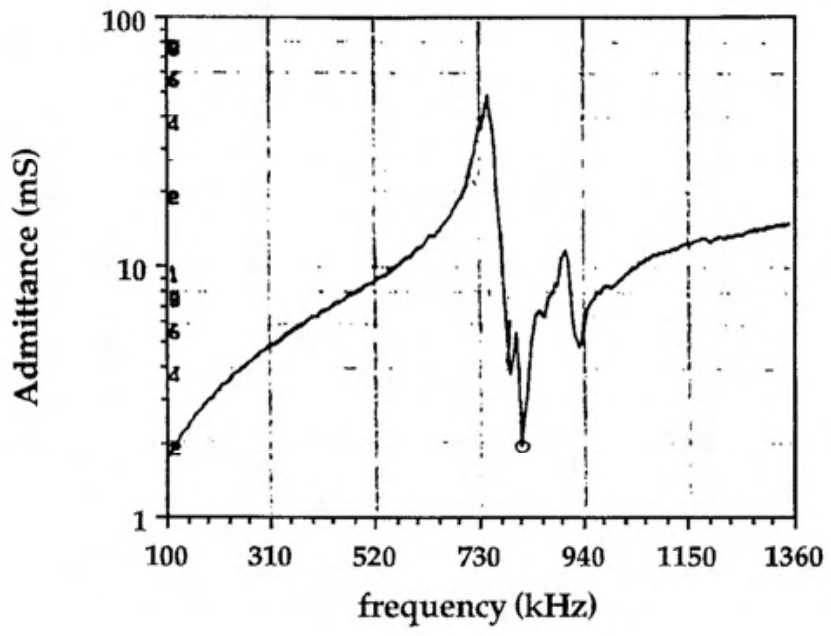

(a)

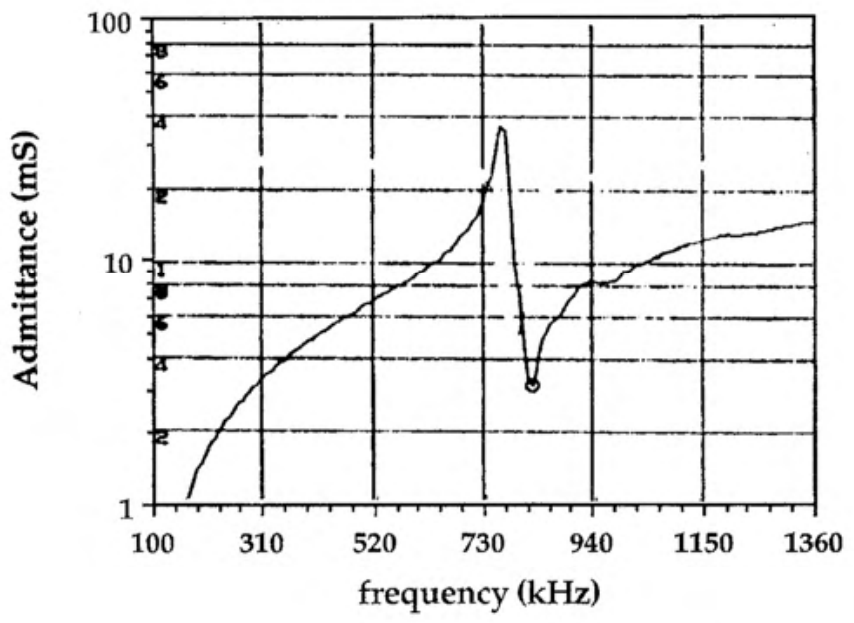

(b)

Fig. 6. Effect of polymer coating: (a) before coating, (b) after coating.

calculated values for both $d_{h}$ and figure of merit are presented in Table I. From these plots, the $d_{h}$ values of the $\mathrm{BBs}$ are found to be one to two orders of magnitude higher than the $d_{h}$ of bulk PZT, with the radially poled BBs displaying the highest $d_{h}$ of all. Similarly the hydrophone figure of merit is three orders of magnitude higher than that of bulk PZT. Finally, evaluation of the results indicates that increasing the electrode separation for top-to-bottom poled spheres results in an increase in the hydrostatic sensitivity.

The amplification of the $d_{h}$ and figure of merit results from the geometry of the spherical BBs. A simplified explanation can be derived using the argument of Timoshenko et al. [25] for the transformation of an applied hydrostatic pressure on a spherical shell into a radial stress $\left(\sigma_{r}\right)$ and two tangential stresses $\left(\sigma_{t}\right)$. This is schematically shown in Fig. 8. These stresses can be calculated using the following

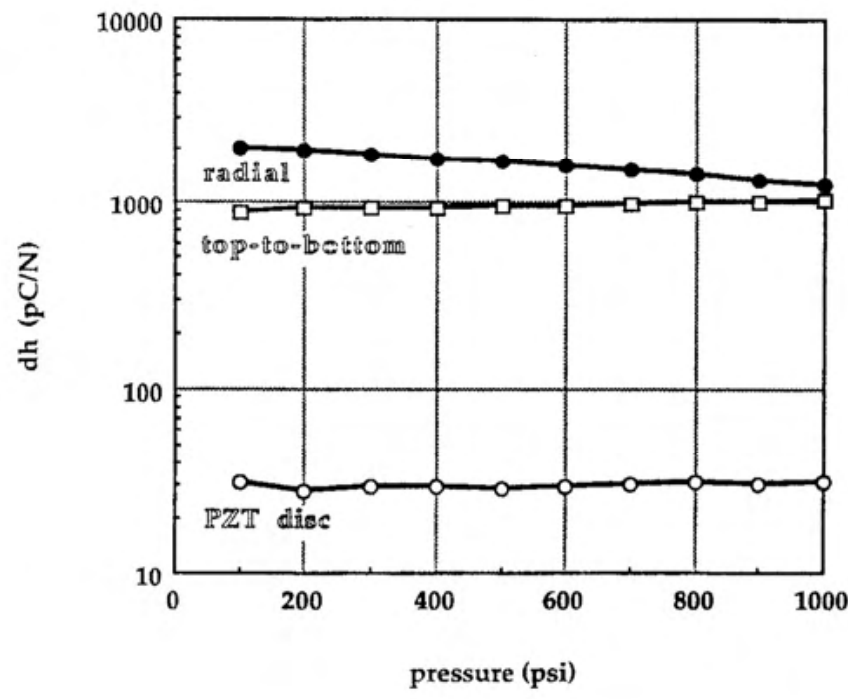

(a)

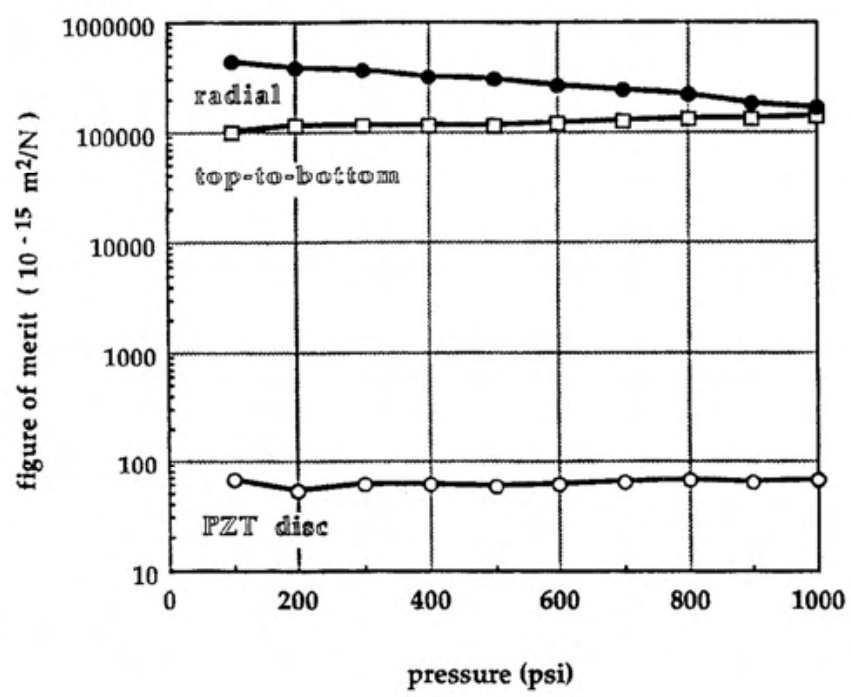

(b)

Fig. 7. Comparison of the hydrostatic sensitivity of the hollow spheres with bulk PZT: (a) effective hydrostatic piezoelectric charge coefficient $\left(d_{h}\right)$ vs. hydrostatic pressure, (b) hydrophone figure of merit $\left(d_{h} \times g_{h}\right)$ vs. hydrostatic pressure.

relations:

$$
\begin{gathered}
\sigma_{r}=\frac{p_{o} r_{o}^{3}\left(r^{3}-r_{i}^{3}\right)}{r^{3}\left(r_{i}^{3}-r_{o}^{3}\right)}-\frac{p_{i} r_{i}^{3}\left(r_{o}^{3}-r^{3}\right)}{r^{3}\left(r_{i}^{3}-r_{o}^{3}\right)} \\
\sigma_{r}=\frac{p_{o} r_{o}^{3}\left(2 r^{3}+r_{i}^{3}\right)}{2 r^{3}\left(r_{i}^{3}-r_{o}^{3}\right)}-\frac{p_{i} r_{i}^{3}\left(2 r^{3}-r_{o}^{3}\right)}{2 r^{3}\left(r_{i}^{3}-r_{o}^{3}\right)}
\end{gathered}
$$

where $P_{o}$ is the outer hydrostatic pressure, $P_{i}$ is the inner hydrostatic pressure, and $\mathrm{r}$ is the radius at which the stress is evaluated. For a thin-walled shell with the wall thickness $\left(t=r_{o}-r_{i}\right)$, assuming $P_{i}=0$, the above equations are 


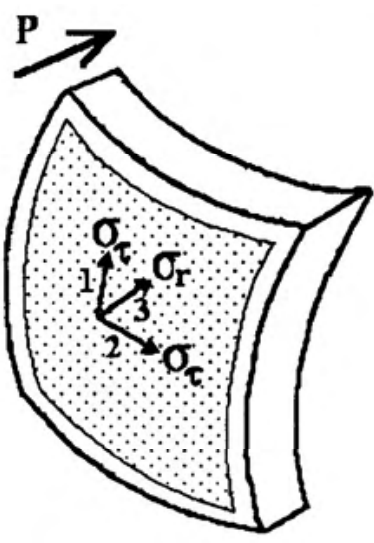

(a)

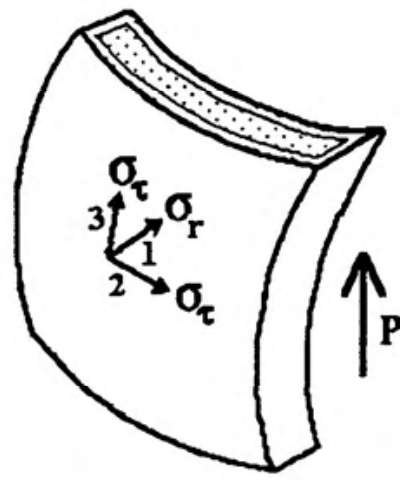

(b)
Fig. 8. Transformation of an applied hydrostatic pressure into radial and transgential stresses: (a) radial poling case, (b) top-to-bottom poling case.

simplified to give average stresses of:

$$
\begin{aligned}
& \sigma_{\tau}=-8.89 * P_{o} \sim-0.50 * P_{o} *(r / t) \\
& \sigma_{\tau}=-0.50 * P_{o} .
\end{aligned}
$$

The ratio $(\mathrm{r} / \mathrm{t})$ is the stress amplification factor which makes hollow spheres important as a sensor. From the known relation between polarization $(\boldsymbol{P})$ and stress $(\sigma)$

$$
\boldsymbol{P}_{3}=d_{31} * \sigma_{1}+d_{32} * \sigma_{2}+d_{33} * \sigma_{3}=-P_{o} * d_{h} .
$$

Using the stress configuration in Fig. 8, and combining (10) with (8) and (9), we obtain the following relations:

$$
\begin{aligned}
\text { radial poling } d_{h} & =0.5 * d_{33}+17.8 * d_{31} \\
\text { top-to-bottom poling } d_{h} & =8.89 * d_{33}+9.39 * d_{31}
\end{aligned}
$$

From (11) a $d_{h}$ of about $2,600 \mathrm{pC} / \mathrm{N}$ is calculated for radial poling assuming that $90 \%$ of the sphere surface is electroded and poled effectively. This is somewhat larger than the average measured value $d_{h}$ of $1800 \mathrm{pC} / \mathrm{N}$. The difference is attributed to the defects in the sphere wall and the imperfect inner electrode. For top-to-bottom poling the model holds better, and (12) gives $d_{h}$ values ranging from $550 \mathrm{pC} / \mathrm{N}$ to $1,190 \mathrm{pC} / \mathrm{N}$ for poled regions of $28.6 \%$ for type-1 to $62 \%$ for type-3. Experimental $d_{h}$ values of 743 $\mathrm{pC} / \mathrm{N}$ to $870 \mathrm{pC} / \mathrm{N}$ were recorded.

Comparison of the BBs with the commercially available hollow sphere transducers for underwater hydrophones indicates that the BBs have an advantage in size, stress amplification factor $(\mathrm{r} / \mathrm{t})$, and cost. Currently, in the market the smallest sphere available has a radius of $\sim 2.8 \mathrm{~mm}$ and a wall thickness of $\sim 800 \mu \mathrm{m}$. The $\mathrm{r} / \mathrm{t}$ ratio is $\sim 3.5$, whereas $\mathrm{BBs}$ have a $\mathrm{r} / \mathrm{t}$ ratio of 17 . Although there are no available data on the $d_{h}$ of the conventional spheres, the higher stress amplification factor of BBs suggests a much higher $d_{h}$ and figure of merit.

\section{CONCLUSIONS}

Small, hollow-sphere piezoelectric transducers can be prepared with an inexpensive and flexible manufacturing process. The main modes of vibration for radially poled PZT spheres are the breathing and thickness modes, which can be tailored over a frequency range of $200 \mathrm{kHz}$ to 20 $\mathrm{MHz}$ by changing the diameter and the wall thickness. The principal modes of vibration for top-to-bottom poled spheres are ellipsoidal, higher order circumferential, and breathing modes. Higher frequency ellipsoidal and higher order circumferential modes coupled to a thickness mode are also observed. Compared to bulk PZT, much higher $d_{h}$ and $d_{h} * g_{h}$ values are obtained with the BB transducer design.

\section{ACKNOWLEDGMENTS}

We thank the Georgia Institute of Technology, USA, and IEMN, Department ISEN, France, for letting us use their facilities.

\section{REFERENCES}

[1] B. Jaffe, W. R. Cooke, and H. Jaffe, Piezoelectric Ceramics, New York: Academic Press, 1971, pp. 135-183.

[2] K. A. Klicker, J. V. Biggers, and R. E. Newnham, "Composites of PZT and epoxy for hydrostatic transducer applications," $J$. Amer. Ceram. Soc., vol. 64, pp. 5-9, 1981.

[3] T. R. Gururaja, R. E. Newnham, K. A. Klicker, S. Y. Lynn, W. A. Schulze, T. R. Shrout, and L. J. Bowen, "Composite piezoelectric transducers," Proc. IEEE Ultrason. Symp., vol. 2, 1980, pp. 576-581.

[4] Q. C. Xu, S. Yoshikawa, J. Belsick, and R. E. Newnham, "Piezoelectric composites with high sensitivity and high capacitance for use at high pressures," IEEE Trans. Ultrason., Ferroelect., Freq. Contr., vol. 38 , no. 6, pp. 634-639, 1991.

[5] A. Dogan, "Flextensional moonie and cymbal actuators," Ph.D. dissertation, The Pennsylvania State Univ., University Park, 1994.

[6] R. Meyer, Jr., H. Weitzing, Q. Xu, Q. Zhang, and R. E. Newnham, "Lead zirconate titanate hollow sphere transducers," $J$. Amer. Ceram. Soc., vol. 77, no. 6, pp. 1669-1672, 1994.

[7] C. E. Bond, Biology of Fishes. Philadelphia: Saunders, 1979.

[8] S. Hanish, "Theory of a very thin piezoceramic hollow sphere underwater sound radiator," NRL Rep. 5267. Washington, D.C.: Naval Research Laboratory, 1959.

[9] L. E. Ivey, "NRL-USRD Series F42 Omnidirectional Standard Transducers," Underwater Sound Reference Detachment. Orlando, FL: Naval Research Laboratory, 1979.

[10] J. W. Holloway, "Omnidirectional high sensitivity hydrophone," U.S. Patent 3,805,226, 1974.

[11] S. L. Ehrlich, "Spherical acoustic transducer," U.S. Patent $3,732,535,1973$.

[12] W. L. Clearwaters, L. T. Einstein, P. F. Radics, Jr., and J. W. Soderberg, "Electrically steerable spherical hydrophone array," U.S. Patent 4,203,162, 1980.

[13] S. Klein, "Omnidirectional transducer of elastic waves with a wide pass band and production process," U.S. Patent 4,782,471, 1988.

[14] S. A. Fisher, "Omni-directional hydrophone," U.S. Patent $5,155,707,1992$

[15] D. Vilkomerson and D. Lyons, "A system for ultrasonic beaconguidance of catheters and other minimally-invasive medical devices," IEEE Trans. Ultrason., Ferroelect., Freq. Contr., vol. 44, no. 1, pp. 27-35, 1997. 
[16] G. R. Lockwood, D. H. Turnbull, and F. S. Foster, "Fabrication of high frequency spherically shaped ceramic transducers," IEEE Trans. Ultrason., Ferroelect., Freq. Contr., vol. 41, no. 2, pp. 231-235, 1994

[17] L. B. Torobin, "Methods of making hollow, porous microspheres," U.S. Patent 4,671,909, 1987.

[18] R. B. Clancy, T. H. Sanders, Jr., and J. K. Cochran, "Fabrication of hollow nickel spheres and low density syntatic foams," in Light Weight Alloys for Aerospace Applications II, E. W. Lee and N. J. Kim, Eds. Warrendale, PA: The Minerals, Metals and Materials Society, 1991, pp. 477-485.

[19] A. T. Chapman, J. K. Cochran, Jr., J. M. Britt, and T. J. Hwang, "Thin-wall hollow spheres from slurries," DOEECUT Program, ORNL Subcontent 86X-22043C, Annual Reports, 1987, 1988, 1989. Washington, D.C.: Department of Energy.

[20] J. T. Fielding, Jr., D. Smith, R. Meyer, Jr., S. Trolier-McKinstry, and R. E. Newnham, "Characterization of PZT hollow sphere transducers," IEEE Int. Symp. Appl. Ferroelec., 1994, pp. 202205 .

[21] A. C. Hladky-Hennion and J. N. Decarpigny, "Finite element modelling of active periodic structures: application to 1-3 piezocomposites," J. Acoust. Soc. Amer., vol. 94, pp. 621-635, 1993.

[22] B. Hamonic, J. C. Debus, J. N. Decarpigny, D. Boucher, and B. Tocquet, "Analysis of a radiating thin-shell sonar transducer using the finite element method," J. Acoust. Soc. Amer., vol. 86 , pp. $1245-1253$, Oct. 1989.

23] A. C. Hladky-Hennion and J. N. Decarpigny, "Application of the finite element method to the modeling of $2 \mathrm{D}$ and $3 \mathrm{D}$ passive or active structures," Ultrason. Int. Conf. Proc., 1991, pp. 415-418.

[24] D. A. Berlincourt, D. R. Curran, and H. Jaffe, "Piezoelectric and piezomagnetic materials and their function in transducers," in Physical Acoustics, Vol. 1, Part A, W. P. Mason, Ed. New York: Academic Press, 1964, pp. 169-257.

[25] S. Timoshenko and J. N. Goodier, Theory of Elasticity. New York: McGraw Hill, 1951.

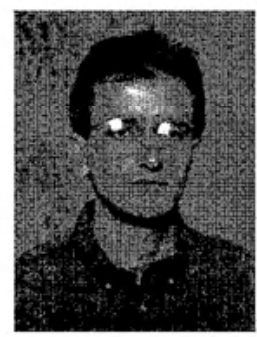

Sedat Alkoy was born in Akhisar, Turkey, on May 10, 1970. He received the B.S. degree in metallurgical engineering in 1992 and the M.S. degree in materials science in 1994, both from Istanbul Technical University, Istanbul, Turkey.

He is currently a Ph.D. student at the Pennsylvania State University, University Park, PA. His research interests are electronic ceramics, development and design of sphere transducers, and periodic composite structures. He is a member of the IEEE Ultrasonics, Ferroelectrics and Frequency Control Society (UFFC) since 1996.

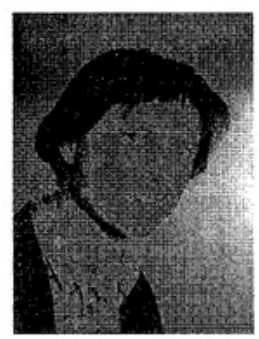

Anne-Christine Hladky was born in Lille France, in 1965. She was awarded the diplome d'ingenier (five-year engineering degree) of the Institut Superiur d'Electronique du Nord in 1987 and the Ph.D. degree in materials science from the Universite des Sciences et Techniques de Lille, in 1990.

She is currently a researcher at the CNRS. Her main research interest is the modeling of acoustic structures, using finite element method, and particularly periodic structures and smart materials. She is a member of the French Acoustical Society (SFA).

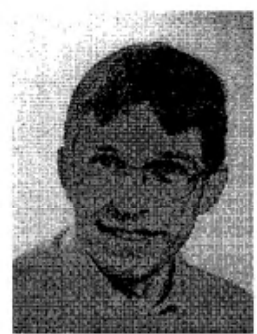

Philippe Langlet was awarded the engineering degree from the Institut Superiu d'Electronique du Nord (ISEN) in 1989 and the $\mathrm{Ph} . \mathrm{D}$. degree in electronics from the University of Valenciennes et du Hainaut Cambresis in 1993. Ph.D. prepared within the acoustic team of the ISEN department of Institut d'Electronique et de Microelectronique du Nord (IEMN UMR CNRS 9929).

$\mathrm{He}$ presently is a researcher at IEMN and a teacher at ISEN. His research interests include finite element analysis of the propagation of acoustic waves in periodic materials or along the tips of elastic immersed wedges.

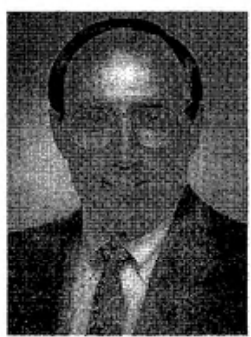

Joe K. Cochran is the B. Mifflin Hood Professor in Materials Science and Engineering at the Georgia Institute of Technology, Atlanta. He received the B.S. degree in 1965 and the M.S. degree in 1968 from the Georgia Institute of Technology, and the Ph.D. from Ohio State University in 1971. All degrees were in ceramic engineering. He was an instructor at the Georgia Institute of Technology from 1966 to 1968 and has been on the faculty since 1971 .

$\mathrm{He}$ is a Fellow of the American Ceramic Society (ACS), recipient of the Hewit Wilson Award from the SE Section of the ACS, and served as intermin director of MSE in 1993. He developed a process for fabricating hollow spheres from powders. His research interests include processing and properties of ceramic foams, premixed radiant burners, rheology of high solid slurries, fine powder processing, and strength of low density materials. His current focus is hollow spheres and foams from low density metals.

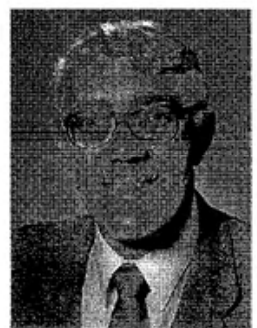

Robert E. Newnham (M'85) was born in Amsterdam, NY, on March 28, 1929. He received the B.S. degree in mathematics in 1950 from Hartwick College, Oneonta, NY, the M.S. degree in physics from the Colorado State University, Fort Collins, CO, a Ph.D. in physics and mineralogy from the Pennsylvania State University, and a second doctorate in crystallography from the Cambridge University, UK 1960.

$\mathrm{He}$ is ALCOA Professor of Solid State Science and associate director of the Materials

$\mathrm{He}$ is currently with NGK Insulators, Ltd., Nagoya, Japan. He is a member of the IEEE Ultrasonics, Ferroelectrics, and Frequency Control Society (UFFC) since 1996.

Research Laboratory at the Pennsylvania State University, University Park, PA. Previously, he was a staff member of the Laboratory for Insulation Research at the Massachusetts Institute of Technology, Cambridge, MA. His research interests are in structure-property relations, electroceramics, and composite materials for electronic applications. 